\title{
A MODEL OF CREATIVE HERITAGE FOR INDUSTRY: DESIGNING NEW RULES WHILE PRESERVING THE PRESENT SYSTEM OF RULES
}

\author{
Harlé, Honorine; \\ Le Masson, Pascal; \\ Weil, Benoit \\ MINES ParisTech
}

\begin{abstract}
In industry, there is at once a strong need for innovation and a need to preserve the existing system of production. Thus, although the literature insists on the necessity of the current change toward Industry 4.0, how to implement it remains problematic because the preservation of the factory is at stake. Moreover, the question of the evolution of the system depends on its innovative capability, but it is difficult to understand how a new rule can be designed and implemented in a factory. This tension between preservation and innovation is often explained in the literature as a process of creative destruction. Looking at the problem from another perspective, this article models the factory as a site of creative heritage, enabling creation within tradition, i.e., creating new rules while preserving the system of rules. Two case studies are presented to illustrate the model. The paper shows that design in the factory relies on the ability to validate solutions. To do so, the design process can explore and give new meaning to the existing rules. The role of innovation management is to choose the degree of revision of the rules and to make it possible.
\end{abstract}

Keywords: Industry 4.0, Design theory, Innovation

\author{
Contact: \\ Harlé, Honorine \\ MINES ParisTech \\ Centre de Gestion Scientifique \\ France \\ honorine.harle@mines-paristech.fr
}

Cite this article: Harlé, H., Le Masson, P., Weil, B. (2021) ‘A Model of Creative Heritage for Industry: Designing New Rules While Preserving the Present System of Rules', in Proceedings of the International Conference on Engineering Design (ICED21), Gothenburg, Sweden, 16-20 August 2021. DOI:10.1017/pds.2021.15 


\section{INTRODUCTION}

Industry 4.0 has been described as industry that relies on Cyber-Physical Systems (CPS) (Thoben et al. 2017) and in which production is supported by sensors, the Internet of things (IoT), automation, big data, etc. (Lu 2017) so as to acquire desirable properties such as agility in dealing with complexity, modularity, connectivity, process integration, autonomy, high reliability, and robustness (Culot et al. 2020) for mass customization (Aheleroff et al. 2019). In such a highly complex and constrained system, the question of designing new solutions and causing the system to evolve inevitably comes up. At first glance, the production appears to be fully determined and prescribed: all the rules are given and the factory is simply a place for their execution. However, when an improvement in the production process is desired, or when a new and badly understood problem occurs, the operator will intervene and design a new solution. This new rule will need to fix or complete the existing system of rules without perturbing it, in spite of its complexity and uncertainty. Thus, in a factory, and especially in a 4.0 factory, the problem is how to innovate while at the same time preserving the system.

This paper deals with the characteristics of and the means for the design of new rules in the factory. How is one to design a solution that will be integrated into the system and will be valid for all conditions without perturbing or destroying the system? How is one to design something new in the factory while relying upon and preserving its system of rules?

This tension between the old and the new is often presented as a dilemma between tradition and innovation. Innovation is usually presented as "breaking the rules" and as being in contradiction with the past (Aghion et al. 2019; Christensen et al. 2018). However, in an industrial context, especially in Industry 4.0, this dualism does not apply. The alternative seems to be a compromise between innovation and tradition. Innovation of a lower degree can be "non-destructive" or only "incremental," according to the well-known typologies of innovation (Coccia 2017; Hervas-Oliver et al. 2019). However, the factory does not correspond exactly to this view. The factory needs to be a place of conservatism and of tradition to keep the manufacturing system reliable and efficient. At the same time, it is also a place that faces unsolved or new problems.

The literature admits another perspective that sheds new light on the question: creative heritage allows for innovation within tradition (Hatchuel et al. 2019). Creative heritage has the two properties of preserving tradition and of "breaking" traditional rules. A factory can be considered as a place of creative heritage in which the design activity can be presented as a way of innovation. Hence, this paper models the design of a rule in a set of rules seen as creative heritage. Two case studies are presented to illustrate the model. The paper gives a new theoretical framework for understanding design activity in the factory. It shows that the crucial point in a design approach in the factory is the validation of the solution and its robustness. It sheds light on how it is possible to have innovation within tradition and on the means by which this can be achieved. It furthers our understanding of both management and design-oriented activity in the factory.

\section{LITERATURE REVIEW}

\subsection{The factory is rule-based and preserves its system of rules. At the same time, the factory constantly innovates.}

The factory is a system geared toward preservation, as stability of production and robustness of new solutions are essential. It has, however, a tendency to become more and more complex and, thus, constrained; moreover, with greater complexity, the risk of a systemic problem arising that would prevent the manufacturing system from working reliably increases. The unsolved problems and challenges of industrial activities are numerous, and the ability to design and innovate is crucial to the good operation, improvement, and transformation of the factory. The anticipated effects of Industry 4.0 are numerous: to have a dynamic manufacturing system, to increase connectivity, to be smarter, etc. (Wichmann et al. 2019). However, there are still great challenges in the implementation of Industry 4.0 in terms of how to face the increased complexity and find an appropriate means of standardization (Wan et al. 2016; Wichmann et al. 2019). Other issues have been raised, such as the need to move industry toward a responsible model (Liu and De Giovanni 2019; Martinuzzi et al. 2018). There is no single solution to these challenges and, hence, innovation is needed to tackle them. As a symptom of this tension and these dual aims, studies have argued for the need for higher skill levels not only to maintain the system (technical and social skills) but also to improve it and to deal 
with uncertain and unknown situations (skills in complex problem-solving, creativity) (Hecklau et al. 2016; Pfeiffer 2016; Veile et al. 2019).

\subsection{The various ways of considering the relationship between tradition and innovation}

\subsubsection{Innovation as a dilemma between preservation and novelty}

Since the beginning of innovation theory in Economics, the destructive phase has been presented as a famous effect of innovation (Aghion et al. 2019; Huffman 2020). According to the Schumpeterian theory, an innovation is adopted, adapted, replicated by others, completed, brings a cluster of innovation, and finally chases away the existing system (Schumpeter 2013; Wadhwani 2020). This theory was first used to explain the economic cycles observed. However, it has been used more widely to describe the innovation process in several fields and according to various interpretations (Xing and Sharif 2020), e.g., in the sciences (Tierney et al. 2020), in transportation (Kim et al. 2018; Schwalbe 2018), and in the media (Aubert-Tarby et al. 2018). Linked to this theory, the degree of innovation is often measured as the gap between the innovation and the state-of-the-art, suggesting the obsolescence of the latter. An innovation is radical if it adds new value for customers or encapsulates new knowledge (Tiberius et al. 2020). Following this line of argument, an innovation that belongs to the "disruptive" category has the potential to bring about the end of the existing market. According to this view, the wish to innovate faces a dilemma between two extreme positions: preserving the past or entering upon a new path of innovation.

\subsubsection{Innovation as a trade-off between preservation and novelty}

As a possible way to avoid the destruction following innovation, the degree of novelty can be moderated. An incremental innovation is the result of a compromise between conservation and novelty. The lower the degree of innovation is, the more the state-of-the-art will be preserved. A marginal innovation will preserve the system (it will remain almost the same), whereas a "radical" innovation - one significant enough to change the system-will be destructive. Thus, the famous adjective "incremental" qualifies an innovation that does not call into question the existing system but adds a marginal touch of newness (Dewar and Dutton 1986). A "non-destructive" innovation is explicitly conservative and will have a low degree of impact on the existing system (Kim and Mauborgne 2019).

\subsubsection{Innovation within tradition}

Beyond these two positions, the idea of "creative heritage" suggests how innovation can emerge within tradition. In gastronomy, this means creating novelty while relying on and preserving the culinary tradition (Carvajal Perez et al. 2018; Hatchuel et al. 2019). Drawing on the topos and the CK theories, Hatchuel et al. (2019) modeled this particular phenomenon, which is both innovative and conservative.

Finally, there are two extreme positions: creative destruction (rule-breaking) or conservation without novelty. There is an intermediate position: a compromise between innovation and tradition. There is also another original position: innovation within tradition. These regimes can all be found in design activity in certain factories.

\section{RESEARCH QUESTIONS AND METHODOLOGY}

The literature review leads to the following research questions:

RQ1. How should we model innovation in the factory and the various types of interaction between the existing rules and the new one? How is it possible for a new rule to at once preserve the system and cause it to evolve?

With this research question, the paper investigates the evolution of a system of rules and the interaction with the heritage of rules during the design phase of the new rule.

RQ2. What are the specific resources, actors, organizations, and means devoted to the design of a new rule — or the extension of an existing one—in creative heritage? 
This question is intended to shed light on management needs for innovation within tradition in the factory.

The literature review mentions a model of creative heritage for innovating within tradition. This framework seems to be well suited to the factory setting. Hence, the authors propose a theoretical model for understanding in a new way the various types of design activity that occur in a factory and specifically those that foster creative heritage. Then two case studies drawn from different industrial fields - aeronautics and railway maintenance - are presented to illustrate the model.

\section{THE MODEL}

The model relies on Hatchuel et al. (2019), in which the creative heritage of gastronomy is modeled using a CK-topos formalization that uses the CK theory (Hatchuel et al. 2018, 2011) in combination with the topos theory. The usual cases are explored: orthodoxy (the tradition is kept), innovation (the tradition - or the rules - is broken), and compromise (a new local rule). The application of the CK-topos reveals a new case: innovation within tradition, i.e., how creation can emerge from tradition without contradicting it. In the model and throughout the paper, the definition of a "rule" is taken in its large sense as a logical link between two objects, based on the definition commonly used in the IA field: "In a rule-based system, much of the knowledge is represented as rules, that is, as conditional sentences relating statements of facts with one another" (Buchanan and Duda 1983). In a factory, it can have several meanings but concerns all the actions prescribed to the operators: it can be a process, a sub-part of a process, a legal rule for manufacturing, a guideline from the engineering department, etc.

\subsection{Preliminary elements}

The following formal elements are taken from Hatchuel et al. (2019) and adapted to the factory context:

- The tradition of the firm is seen as a set of rules. The rules belong to the knowledge (K-space) of the factory. However, because they are numerous, complex, and aggregated across time, the whole system of rules is not known.

- The building category can be understood as an ideal model, expressed in terms of rules and their interaction. The translation to the rules is not perfect, and sometimes a rule is missing, or there is a contradiction between the rules.

- In the factory, a pre-sheaf on the category is a local solution (i.e., for a particular product or process, for a limited time and set of conditions) which is at the step of concept and which is not validated as a general solution. Hence, the pre-sheaf belongs to the concept space (C-space).

- The sub-object classifier $\mathbf{J}$ defines what makes the category stable. $\mathbf{J}$ appears to be essential: it defines the possibility of making the rules evolve. $\mathrm{J}$ can be interpreted as design-oriented management.

As Hatchuel et al. (2019) noted, the particularity of the model relies on the process of "sheafification," i.e., when a pre-sheaf becomes a sheaf. The category is stable (hence the tradition is kept), and J controls the expansion and enables a new meaning - or an extension of the meaning - for the rule, keeping the tradition. In the factory, sheafification corresponds to the process of validation of a solution or a family of solutions thanks to the new meaning of the rule designed.

\subsection{The CK-topos model of the factory}

We can derive a model for the factory seen as creative heritage with the CK-topos model. In the Cspace, the initial concept corresponds to the search for a solution with the properties $(\mathrm{P} 1, \ldots \mathrm{Pn})$ to tackle a problem that is as yet unsolved. The $\mathrm{K}$-space contains the rules corresponding to the problem and the solutions in the factory (the category) and the known solutions in the manufacturing field. The first partition (in the C-space) is whether or not to keep the category. If the category is not kept, there is a case of radical innovation, i.e., the rules are broken. If the category is kept-in other words, if the rules remain stable - the second partition relies on $\mathrm{J}$ : if it is coarse, then the rule will be applied literally and the tradition will be kept; if it is dense, then another sense of the rule can be unearthed. In this case ( $\mathrm{J}$ dense), the innovation can be local and the system of rules can admit one exception: it is a compromise between tradition and innovation. If the rule admits an extended meaning, a range of new robust solutions appears, in accordance with the heritage that has evolved. For that, in the K-space, 
other knowledge, expertise, skills in various fields are gathered to validate the new meaning of the rule in the general case.

Reasoning: The reasoning is explained in Figure 1.

1. A solution is found for a given problem. At first, it is not validated for a wide variety of conditions; hence, it is called a local innovation.

2. To extend the validity of the solution (for instance, to be sure that it will be valid over the long term, under various physical conditions (temperatures, pressures), for various kinds of users, etc.) and to ensure the robustness of the solution, the rules corresponding to the solution and especially the rules against the solution are exhibited in the K-space: after investigation, the category and its rules become known.

3. Two possibilities: A) The rule is a rediscovered rule. There is already a known solution to the problem. The tradition is maintained.

(or) B) To validate the new local solution, the category has to evolve and the rule should have a new meaning. For this, a validation of the new meaning of the rule is required.

4. The original rule admits a variation in its interpretation. A new meaning comes up. The local solution is now in accordance with the heritage.

5. The pre-sheaf becomes a sheaf (that is, the so-called sheafification): the solution is one particular solution out of a set of new solutions validated by the new meaning of the rule.

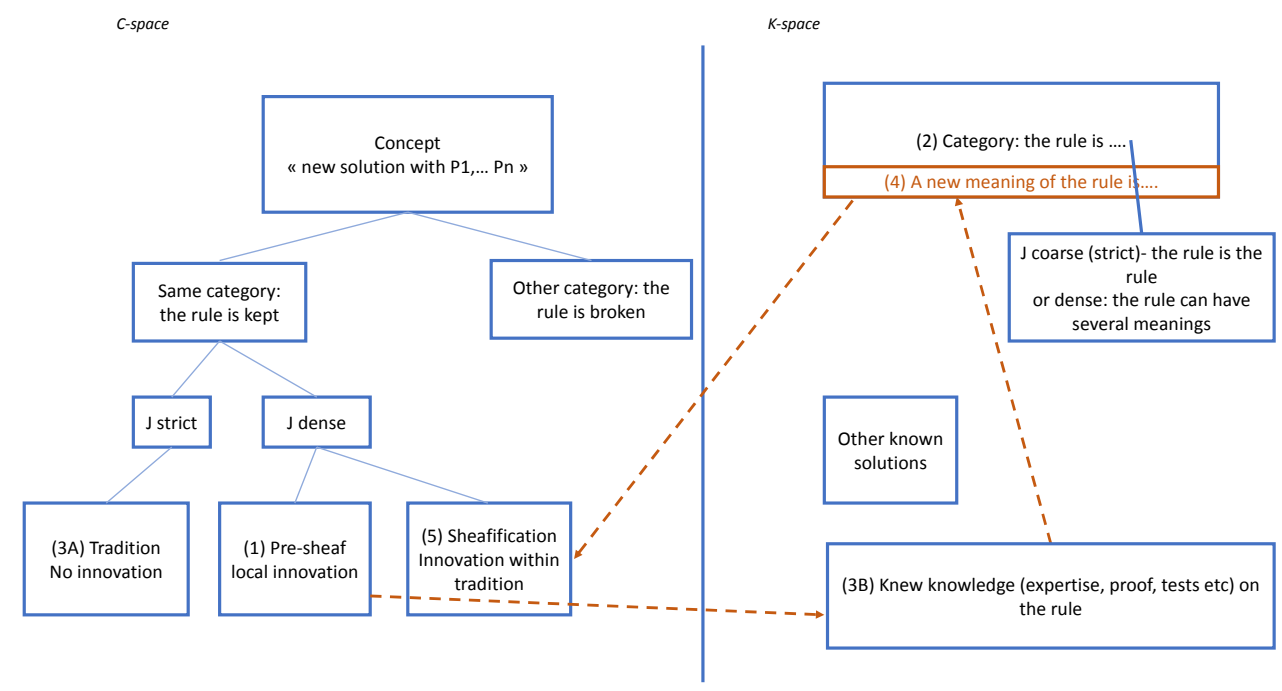

Figure 1. Designing new rules within the tradition: the factory as creative heritage

Caption (figure 1 and the following): The blue boxes refer to the CK theory. The brown box illustrates the process of sheafification in the case of creation heritage. The arrows indicate the sequence of reasoning.

\subsection{Learnings and comments}

The validation at stake: Understanding the factory as a site of creative heritage seems at first to offer a counter-intuitive general result. The model shows that the crucial issue is to validate the solution according to the system of rules, which is not known before. This will ensure that the solution does not perturb the system and that it will be robust. The reasoning starts from an a priori solution, and the exploration in K depends on this solution. Designing new solutions in a system of rules like those in a factory does not consist of listing all the rules in the set of existing rules and imagining and implementing a solution. The system of rules is a priori unknown. The design process rediscovers it. It starts with a problem that can be seen as a symptom of a local crisis in the set of rules. From that point, a pre-solution is more or less immediately designed and alternatives are generated. The pre-solution sheds light on the rules impacted. Then an interaction takes place between the rules to validate it and explore possible concepts. The validation comes from the cross between the solution and the rules that it rediscovers or re-designs. Hence, the generation of a solution is closely linked to the exploration of the corresponding set of rules. This marks a significant difference from the design approach typically 
found in an engineering office, in which an already-known frame is used to design: the set of functions, requirements, limits of conditions, knowledge of the behavior of the components within these limits, etc., is given.

The prediction of the strength and intensity of the adapted management: In this model, " $\mathrm{J}$ " is crucial and determines the type of design and the means devoted to it. It can be a management more ( $\mathrm{J}$ dense) or less ( $\mathrm{J}$ coarse) devoted to design. For $\mathrm{J}$ coarse, the means are limited to the factory and to the ability to look after the rules. J dense can require time, teamwork, and knowledge from fields other than manufacturing. It can also require an ability to sort the project in terms of the scope of its functions and the domain of validity wanted. For example, one might consider a given project as being "local" and thus not requiring a re-consideration of the system of rules, but want a systematic and very robust solution for another project.

The preservation and extension of heritage: According to our model, the notion of "preservation" is wider than mere conservation of the existing rules. It also encompasses a re-discussion of the rules to find a sense that preserves the initial principle of the rule while admitting another dimension.

\section{TWO CASE STUDIES}

Two case studies are presented here to illustrate and enrich our understanding of the model. They are taken from two different industrial fields: a railway maintenance center and an aeronautical plant.

\subsection{The sandbox}

\subsubsection{The case}

At a maintenance center for French regional trains located in Nantes, a virtual suggestion box is used to collect ideas from the operators. One of the suggestions concerned the train's sandbox. This is a box containing some sand to put between the rail and the wheel to increase the adherence of the rail in case of an emergency stop or wet conditions. The sandbox is made of a filler door to put the sand in, a hull to keep the sand, and a pipe from the hull to the rail.

The operator who suggested the idea had observed that the sand in the sandbox tended to become wet and consequently obstruct the mechanism. The operator discovered that the water came from a leak on the filler door of the sandbox. His idea consisted of adding a gutter over the filler door to avoid the rain entering the sandbox. The managers read the problem and the solution. However, in contrast to the immediate validation that occurred in most cases, the managers took some time to answer. Indeed, other possible solutions were investigated because no one could tell if the gutter was the better solution. During this phase, the managers carefully read the engineering rules concerning the sandbox and discovered that there was a seal missing on the filler door. Finally, they decided to add the corresponding seal.

\subsubsection{Analysis using the model}

The case is illustrated in Figure 2. The starting point was the proposal of the water gutter as a local solution (A). The managers and the operator then carefully investigated the maintenance rules for the sandbox and other possible solutions that they could imagine (B). Then they discovered an ongoing but forgotten rule (the category) that was not being applied. Finally, they chose the solution indicated by the rule and came back to the seal $(\mathrm{C})$.

\subsubsection{Comments}

The first solution proposed by the operator was the starting point of the reasoning. The next step consisted of discovering other solutions and at the same time looking for the rules and the blocking points that prevented one of the solutions from being chosen. Finally, the re-discovery of the maintenance rule guided the choice for the solution that had already been validated. 


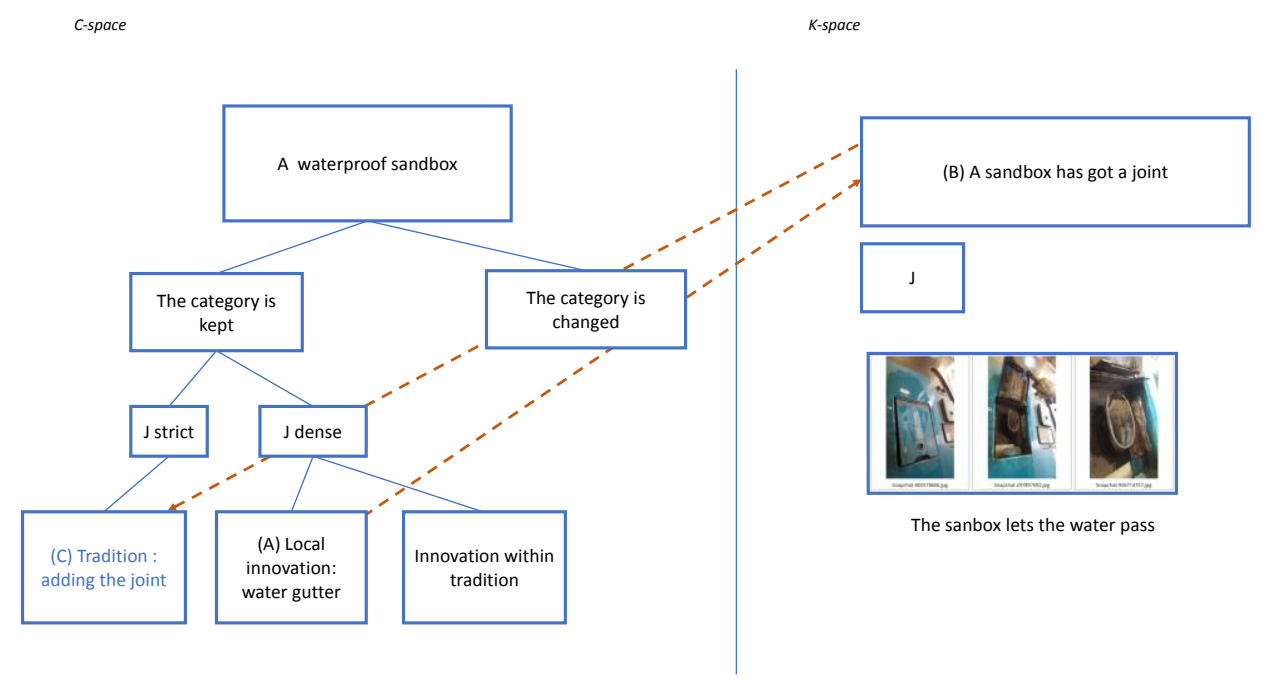

Figure 2. Reasoning to rediscover the rules to solve the leak in the sandbox

\subsection{The safety mattresses}

\subsubsection{The case}

In the Airbus factory in Saint-Nazaire, several workshops were held to improve the safety of the factory. The team first considered ways to improve safety by complying with the usual processes and norms. Then an innovative design approach led to the solution of using safety mattresses, even though the safety norms usually forbade this solution. In our case, the team in charge of the problem proved that adding a second independent line was a better solution than the one in place. The mattresses were accepted.

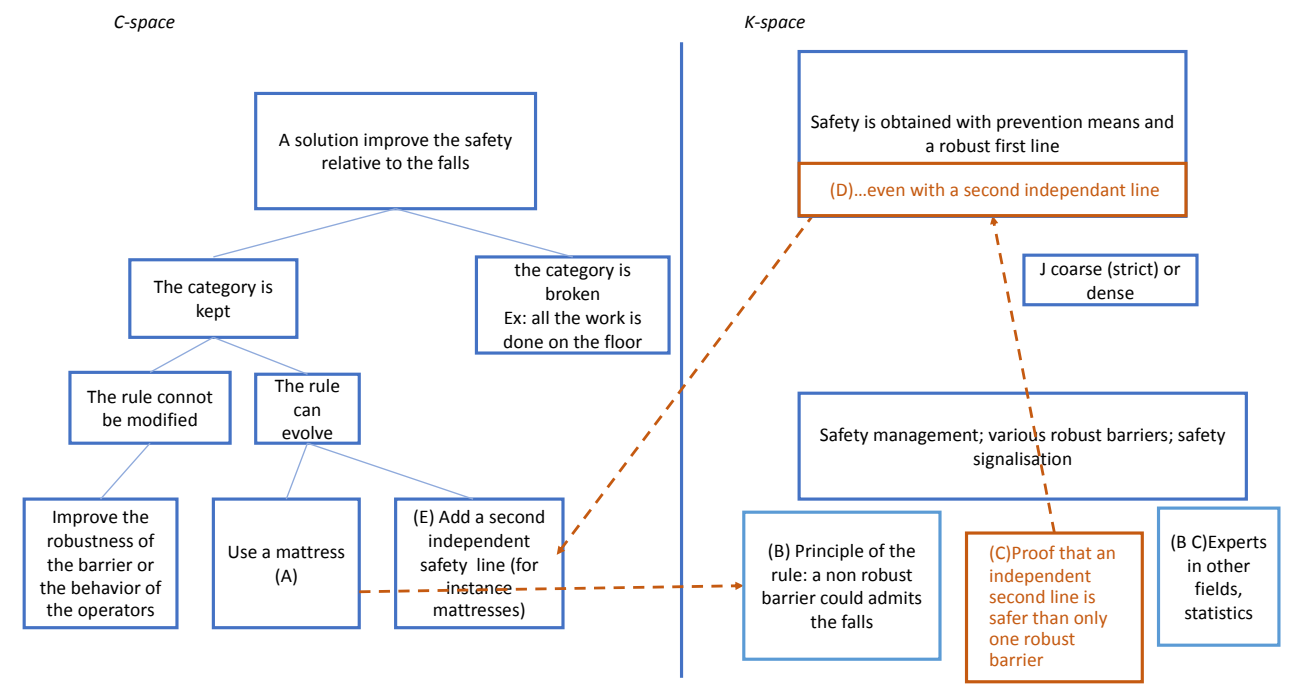

Figure 3. Reasoning for the validation of the safety mattresses: a case of sheafification

\subsubsection{Analysis using the model}

The reasoning is illustrated in Figure 3 and can be described as follows: to improve safety, the team explored other fields (nuclear and airplane safety) and came across the concept of the second independent line. They thought about using a safety mattress to prevent injuries after a fall (A). They consulted the experts, who answered that safety mattresses were forbidden in the factory. The rules only allowed for a robust first line to prevent falls and a few other means that had been adopted (warning signs, safety training, instruction, etc.) (B). Indeed, a second independent safety line would suggest that the first line allowed falls and was not robust. They investigated the principle of the norm, produced new statistical calculations, and proved that an independent second line added to a robust first line was indeed safer than one robust first line (C): it drastically reduces the risk of heavy injury 
in case of falls. Then the original rule was expanded to admit the second line (D). This validated all the particular solutions referring to a second independent line $(\mathrm{E})$.

\subsubsection{Comments}

As the proof of the consistency of the new sheaf was valid in the general case, all the particular solutions corresponding to the definition of the "independent second line" became valid. The mattresses appeared to be one of the possible solutions. Taken as a general rule, the solution could be applied not only locally but also in all circumstances where there was only a robust barrier.

\section{RESULTS}

\subsection{Result 1: The type of innovation depends on the interaction with the system of rules}

Modeling the possible interactions between the new solution and the heritage of rules makes various types of innovation appear.

- On the one hand, the solutions can fall under the tradition: in this case, there is no new rule. The validation of the solution revealed that it complied with the existing system of rules (the tradition) or-in the sandbox case-rediscovered the existing rules. This type of innovation is well known in the factory. The solutions are generally quickly validated and implemented. An intense rhythm of new solutions like this is often encouraged, especially in a continuous improvement approach. Tips, tricks, and bricolage most of the time belong to this category.

- On the other hand, the solutions can appear to be totally new and without any link to the existing system of rules. The new rule breaks and replaces the system of rules, as is the case in a revolutionary production system or in a new way of manufacturing. This type of project requires a wide and deep design process that can include the factory but also concerns the engineering department and potentially other organizations, for instance, the company's strategy team.

- The solutions can be validated locally for a small range of validity (for instance, for a particular product or for one machine during a determined time). In the factory, this status is a sort of derogation, as the solution is only robust within a small perimeter for a short time.

- Lastly, there is a class of solutions that neither comply with the existing rules nor break them. They re-interpret the rules or extend them, which means that they give them a new sense or a new meaning that has not been seen before. This type of solution is subtler to validate, and the engineering department can potentially support the design process and its validation. The organization for that process is developed in the next paragraph.

\subsection{Result 2: The management and skills for creative heritage}

The role of the management and the designers in this type of innovation is to guide the interaction between the new solution and the tradition. In terms of resources, it can be very useful to have access to experts who know perfectly what the exact sense of the rule is, what is admitted or forbidden, and what was the original reason for the rule. However, this condition is not sufficient. The critical point is not only to know the rules but also to guide the search through all the rules of the system to determine which one is problematic and should be rethought or extended. An investigation to find the critical one is required. Furthermore, to design the proof to validate the rule in the general case or to design other strategies to validate a claim involves bringing new measures, developing prototypes, and running tests. As it involves various skills, the design and validation process must be done in a team that has the specific qualities required to know how to "interact" with and revise the rules.

All these conditions require time and space that is not necessarily allocated for smaller innovations, as easiness to implement is usually one of the criteria for success of an innovation in the factory. Finally, the managers of the factory have to support this design effort to make it possible and to make the heritage "creative."

\section{DISCUSSION AND CONCLUSION}

A modeled example of creation within tradition in the factory: The model and the case studies show the mechanism behind a site of creative heritage such as a factory. This offers a new perspective 
on the interaction between innovation and tradition. The sheafification allows a very different phenomenon than the usual antagonism of creation vs. destruction. The rules can evolve without any contradiction with the heritage of rules, and the design of the solution does not "destroy" or negatively impact the system of rules. In the same way, in this frame, the idea of innovations being either "incremental" or "radical" loses its meaning. In a creative heritage context, an "incremental" innovation could belong to the tradition and comply with the rules. It could also-but very differently - belong to the tradition but expand its rules. On the contrary, the sheafification process suggests that an innovation can be "radical" by virtue of the newness of the new meaning of the rule, without breaking the rules or destroying the tradition.

A new model for understanding the factory: Moreover, this paper models the factory as a system of rules constituting creative heritage. This gives a new perspective on the innovation process, as the stake in the innovation process in creative heritage is to validate the solution and to make it robust and not necessary to be strongly innovative. One can also notice that in our model, the "conjunction phase" mentioned in the CK theory (Hatchuel et al. 2011) corresponds here to the validation of the solution (the pre-sheaf) regarding the rules, the careful adequacy between the system of rules and the solution.

A model relevant to Industry 4.0: Automation makes the rules numerous and the system fully deterministic. Moreover, the variety and nature of technologies increase the complexity of the system (Brocal et al. 2019) and its evolution is problematic: an improvement can put the system at risk if it is not robust, but at the same time, the system (hence the category) is less and less easy to understand. Hence, the model shows that the validation of a new solution is particularly crucial and informative regarding the conditions of the validation. In particular, the role of operators in Industry 4.0 becomes clearer: the literature already underlines the need to have technical and social skills, but also the need for skills in creativity and problem-solving (Hecklau et al. 2016; Pfeiffer 2016; Veile et al. 2019). The model presented in this paper refines the operators' role: they need to acquire a sort of agility to be able to "navigate" the system of rules, investigate the rules that are re-questioned and the rules that present obstacles to improvement, call the right experts, or venture beyond the factory into related fields to gain access to new knowledge about the question. The operator is in charge of demonstrating rigorously that the improvement does not put the system at risk.

A comprehension of the evolution of a rule: This paper shows how a rule - in a broad meaning evolves and contributes to our understanding of what "expanding the rule" involves. It gives insights into the apparition of new "interpretations" or "meanings" that can give rise to a paradoxical situation in which a "new" rule that gives a totally new meaning to the whole system of rules can appear. At the same time, this new rule emerges from tradition and from the system of rules itself.

\section{ACKNOWLEDGMENT}

We thank David Mulrooney, Ph.D., from Edanz Group (https://en-author-services.edanz.com/ac) for editing a draft of this manuscript.

\section{REFERENCES}

Aghion P, Bergeaud A, Boppart T., Klenow PJ, Li H (2019) Missing growth from creative destruction. Am. Econ Rev 109:2795-2822. https://doi.org/10.1257/aer.20171745

Aheleroff S, Philip R, Zhong RY, Xu X (2019). The degree of mass personalisation under Industry 4.0. Procedia CIRP 81:1394-1399. https://doi.org/10.1016/j.procir.2019.04.050

Aubert-Tarby C, Escobar OR, Rayna T (2018). The impact of technological change on employment: The case of press digitisation. Technol Forecast Soc Change 128:36-45. https://doi.org/10.1016/j.techfore.2017.10.015

Brocal F, González C, Komljenovic D, Katina PF, Sebastián MA (2019) Emerging risk management in Industry 4.0: An approach to improve organizational and human performance in the complex systems. Complexity 2019:e2089763. https://doi.org/10.1155/2019/2089763

Buchanan BG, Duda RO (1983) Principles of rule-based expert systems. In: Yovits MC (ed) Advances in Computers. Elsevier, pp. 163-216. https://doi.org/10.1016/S0065-2458(08)60129-1

Carvajal Perez D, Masson PL, Weil B (2018) Managing Dom Pérignon's creative heritage: Modelling and organising the transmission of knowledge for generativity. Université Paris Sciences et Lettres.

Christensen CM, McDonald R, Altman EJ, Palmer JE (2018) Disruptive innovation: An intellectual history and directions for future research. J Manag Stud 55:1043-1078. https://doi.org/10.1111/joms.12349 
Coccia M (2017) Sources of technological innovation: Radical and incremental innovation problem-driven to support competitive advantage of firms. Technol Anal Strateg Manag 29:1048-1061.

Culot G, Nassimbeni G, Orzes G, Sartor M (2020) Behind the definition of Industry 4.0: Analysis and open questions. Int J Prod Econ 226:107617. https://doi.org/10.1016/j.ijpe.2020.107617

Dewar RD, Dutton JE (1986) The adoption of radical and incremental innovations: An empirical analysis. Manag Sci 32:1422-1433.

Hatchuel A, Le Masson P, Reich Y, Subrahmanian E (2018) Design theory: A foundation of a new paradigm for design science and engineering. Res Eng Des 29:5-21. https://doi.org/10.1007/s00163-017-0275-2

Hatchuel A, Le Masson P, Reich Y, Weil B (2011) A systematic approach of design theories using generativeness and robustness. In: DS 68-2: Proceedings of the 18th international conference on engineering design (ICED 11), Impacting society through engineering design, Vol. 2: Design theory and research methodology, Lyngby/Copenhagen, Denmark, pp. 87-97.

Hatchuel A, Masson PL, Weil B, Carvajal-Perez D (2019) Innovative design within tradition: Injecting topos structures in C-K theory to model culinary creation heritage. Proc Des Soc Int Conf Eng Des 1:1543-1552. https://doi.org/10.1017/dsi.2019.160

Hecklau F, Galeitzke M, Flachs S, Kohl H (2016) Holistic approach for human resource management in Industry 4.0. Procedia CIRP 54:1-6. https://doi.org/10.1016/j.procir.2016.05.102

Hervas-Oliver JL, Sempere-Ripoll F, Estelles-Miguel S, Rojas-Alvarado R (2019) Radical vs incremental innovation in Marshallian Industrial Districts in the Valencian Region: What prevails? Eur Plan Stud 27:1924-1939.

Huffman GW (2020). An analysis of the importance of both destruction and creation to economic growth. J Monet Econ 116:166-183. https://doi.org/10.1016/j.jmoneco.2019.08.008

Kim K, Baek C, Lee JD (2018) Creative destruction of the sharing economy in action: The case of Uber. Transp. Res. Part Policy Pract 110:118-127. https://doi.org/10.1016/j.tra.2018.01.014

Kim WC, Mauborgne R (2019) Nondisruptive creation: Rethinking innovation and growth. MIT Sloan Manag Rev 60:46-55.

Liu B, De Giovanni P (2019). Green process innovation through Industry 4.0 technologies and supply chain coordination. Ann Oper Res 1-36.

Lu Y (2017) Industry 4.0: A survey on technologies, applications and open research issues. J Ind Inf Integr 6:110. https://doi.org/10.1016/j.jii.2017.04.005

Martinuzzi A, Blok V, Brem A, Stahl B, Schönherr N (2018) Responsible research and innovation in industryChallenges, insights and perspectives. Multidisciplinary Digital Publishing Institute.

Pfeiffer S (2016) Robots, Industry 4.0 and humans, or why assembly work is more than routine work. Societies 6:16.

Schumpeter JA (2013) Capitalism, socialism and democracy. Routledge.

Schwalbe U (2018) Schneider Henrique: Creative destruction and the sharing economy: Uber as disruptive innovation. J Econ 124:93-96. https://doi.org/10.1007/s00712-017-0589-6

Thoben KD, Wiesner S, Wuest T (2017) "Industrie 4.0" and smart manufacturing - A review of research issues and application examples. Int J Automation Tech 11:4-16. https://doi.org/10.20965/ijat.2017.p0004

Tiberius V, Schwarzer H, Roig-Dobón S (2020) Radical innovations: Between established knowledge and future research opportunities. J Innov Knowl https://doi.org/10.1016/j.jik.2020.09.001

Tierney W, Hardy JH, Ebersole CR, Leavitt K, Viganola D, Clemente EG, Gordon M, Dreber A, Johannesson M, Pfeiffer T, Uhlmann EL (2020). Creative destruction in science. Organ Behav Hum Decis Process 161:291-309. https://doi.org/10.1016/j.obhdp.2020.07.002

Veile JW, Kiel D, Müller JM, Voigt KI (2019) Lessons learned from Industry 4.0 implementation in the German manufacturing industry. J Manuf Tech Manag 31:977-997. https://doi.org/10.1108/JMTM-08-2018-0270

Wadhwani RD (2020) Gales, streams, and multipliers: Conceptual metaphors and theory development in business history. Enterp Soc 21:320-339. https://doi.org/10.1017/eso.2019.56

Wan J, Tang S, Shu Z, Li D, Wang S, Imran M, Vasilakos AV (2016) Software-defined industrial internet of things in the context of industry 4.0. IEEE Sens J 16:7373-7380.

Wichmann RL, Eisenbart B, Gericke K (2019) The direction of industry: A literature review on Industry 4.0. Proc Des Soc Int Conf Eng Des 1:2129-2138. https://doi.org/10.1017/dsi.2019.219

Xing JL, Sharif N (2020) From creative destruction to creative appropriation: A comprehensive framework. Res Policy 49:104060. https://doi.org/10.1016/j.respol.2020.104060a 